\title{
Airway Management in a Child Presenting with Syngnathia for Surgical Correction
}

\author{
Aruna Chandak ${ }^{1}$, Bhakti Ravindra Patil ${ }^{2}$ \\ ${ }^{1}$ Department of Anaesthesia, JNMC, Sawangi, Meghe, Wardha, Maharashtra, India. ${ }^{2}$ Department of Anaesthesia, JNMC, \\ Sawangi, Meghe, Wardha, Maharashtra, India.
}

\section{INTRODUCTION}

Syngnathia is a rare disorder characterized by bony fusion of maxilla and mandible which can be unilateral, or bilateral.1,2,3,4 Only 24 cases have been reported since 1936. Airway management in case of surgery for syngnathia varies from observation or sedation only, up to full airway control. It is a formidable task for anaesthetist to manage anticipated difficult intubation.

Management of difficult airway is challenging task for anaesthesiologist. We present a case of $5 \mathrm{yr}$. old female with syngnathia with a bony fusion of maxilla and mandible on right side. Multidisciplinary approach is used to manage the airway with step wise anticipation of each complication. Child is premedicated with oral promethazine, nebulisation given, followed by FOB by maintaining spontaneous ventilation in the child.

\section{PRESENTATION OF CASE}

A 5-year-old female patient, weighing 15 Kgs., presented to SPDC Sawangi Meghe, Wardha with complaints of inability to open her mouth since childhood (figure 1). The child was referred from government hospital Hyderabad where CT scan was done. The child was born of caesarean section (oligohydramnios) with congenital inability to open the mouth. There were no other congenital anomalies and comorbid conditions in parents but there is history of consanguineous marriage from maternal, paternal side of the child as well as within the parents. Patient was awake and active. Her haematological and biochemical investigations were within normal limits. On extraoral examination, face showed asymmetrical flattening of face on right side with no lateral excursion movement of temporomandibular joint, and mouth opening is absent. No other syndromic feature was present, intraoral examination could not be done due to absence of mouth opening.

CT scan of face showed bony fusion of maxilla and mandible on the right side. Surgical correction was planned with release of syngnathia by instrumentation and bilateral coronoidotomy.

In preoperative preparation the child was given syrup promethazine as a sedative at bedtime and in morning on the day of surgery so that the child is calm and sedated. Child was nebulised with LOX $4 \%$ and bronchodilator in preoperative room.
Corresponding Author:

Dr. Bhakti Patil,

Department of Anaesthesiology,

JNMC, Sawangi (Wardha-442001),

Maharashtra, India.

E-mail: 93bhakti@gmail.com

DOI: $10.14260 / j e m d s / 2020 / 286$

Financial or Other Competing Interests: None.

How to Cite This Article:

Chandak A, Patil BR. Airway management in a child presenting with syngnathia for surgical correction. J. Evolution Med. Dent. Sci. 2020;9(15):1316-1318, DOI: $10.14260 / \mathrm{jemds} / 2020 / 286$

Submission 29-01-2020,

Peer Review 24-03-2020,

Acceptance 30-03-2020,

Published 13-04-2020.
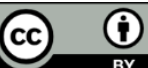
Difficult airway cart, emergency drugs kit (figure 2) including adrenaline, atropine, cardiovascular drugs, bronchodilators were kept ready. High risk consent for anaesthesia and postoperative ventilator support consent was taken $^{5}$. As difficult intubation was anticipated cricothyroid puncture and tracheostomy was kept as a last resort. All the operation theatre team including nurse staff, surgeons, anaesthetists were aware about severity of situation if intubation was not possible and also ENT surgeons were ready for tracheostomy if needed 6 . Awake intubation with fibreoptic bronchoscope was planned.

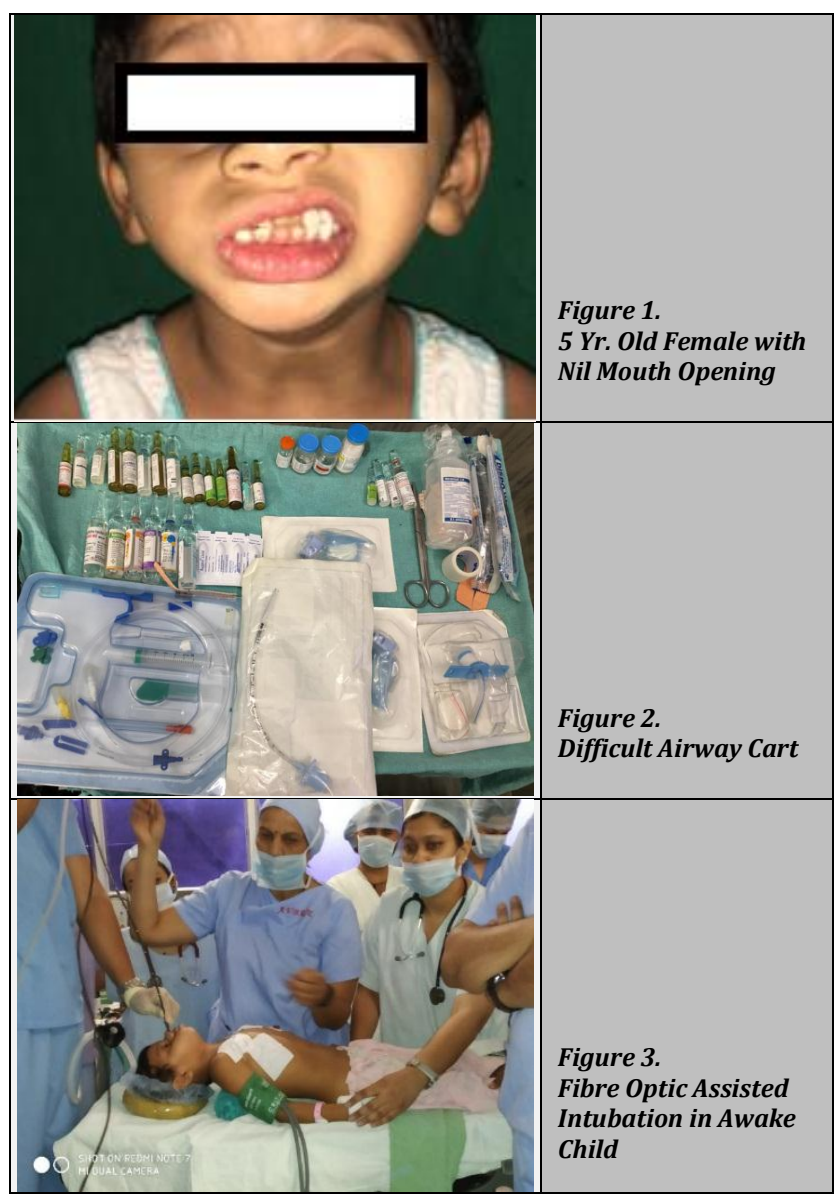

Child was brought to operation theatre and multipara monitors were attached (ECG, SPO2, Blood pressure, pulse rate, ETCO2, respiratory rate). Awake fibreoptic was performed with administration of incremental doses of ketamine (figure 3), $4.5 \mathrm{~mm}$ cuffed tube was guided via FOB connected to JR circuit. Injection propofol $2 \mathrm{mg} / \mathrm{Kg}$ was given followed by muscle relaxant Atracurium $0.5 \mathrm{mg} / \mathrm{Kg}$. Patient was maintained on oxygen/nitrous oxide/sevoflurane.

Tube was secured with tube stitch. Tube dislodgment or intraop extubation was anticipated while intraoral manipulation and coronoidotomy, and so continuous vigilance of tubemark was done. Proper care to prevent hypothermia was taken by warming blanket and fluids were administered according to weight of child. The anticipated time for surgery was 2-3 hours. Patient was accidently extubated when surgeon was cleaning oral cavity with betadine, immediately saturation started to fall with falling capnography, bradycardia, Inj. Atropine was given and patient was intubated orally later when vitals became stable nasally intubated and surgery was continued. After procedure patient was shifted with tube in situ, and was extubated next day morning.

\section{DISCUSSION}

Syngnathia is a extremely rare condition, involving abnormal development of splanchnocranium which is part of skull that is derived from brachial arches. Severity ranges from single mucosal band synaechiae $7,8,9$ to complete bony fusion called as synostosis which can be unilateral or bilateral. Airway management in this case needs a multidisciplinary approach that is involvement of all operation theatre staff including nurses, surgeons, paediatricians along with the anaesthetist.

Expected difficult airway which is assessed preoperatively should be meticulously planned for management step wise including what should be next step if tracheal intubation is failed, whether the child can be woken up or tracheostomy will be necessary, and accordingly the plan should efficiently be communicated to theatre team and surgeons. Difficult airway equipment's including all sizes tubes appropriate for age and smaller, FOB, cricothyroid puncture set, tracheostomy tubes and set, ventilating bougies should be kept checked and kept ready on cart.

The most important principle in managing difficult airway in children is to maintain spontaneous ventilation until airway is secure.

Awake intubation is difficult in children so, the child must be anesthetized by intravenous agent or inhalational agent. ${ }^{10}$ This child was anesthetized by incremental doses of ketamine and after proper positioning of child for FOB maintained spontaneous ventilation and was intubated with $4.5 \mathrm{~mm}$ cuffed tube nasally and later on was given inducing dose of propofol and muscle relaxant and was ventilated. Patient received nebulisation with Lignocaine $4 \%$ and salbutamol bronchodilator and premedication as promethazine syrup in preoperative room and Inj. glycopyrrolate $0.004 \mathrm{mg} / \mathrm{Kg}$ and Inj. midazolam $0.5 \mathrm{mg} / \mathrm{Kg}$ on OT table via 24-gauge intravenous access following which the patient was calm and sedated, maintained spontaneous ventilation while FOB.

Patient was ventilated by JR circuit with flows maintained on $3 \mathrm{~L} / \mathrm{min}$ oxygen and $3 \mathrm{~L} / \mathrm{min}$ of nitrous oxide. Patient was maintained on sevoflurane and atracurium for muscle relaxation. Warming blanket was covered in order to prevent hypothermia and fluids were administered according to holiday Segar's formula.11,12 Surgical correction by instrumentation and bilateral coronoidotomy was undertaken, with minimal blood loss. Haemostasis was achieved after surgery, the high probability of dislodgement of tube was taken into account while coronoidotomy for which vigilance of tube mark was done and surgeons were alarmed for airway while the procedure. (accidental extubation occurred while surgeon cleaned mouth via betadine gauze after coronoidotomy, pt was reintubated through oral route as mouth opening was achieved, later nasal tube was placed, secured and surgery was continued)

Intraoperatively analgesia was provided by inj. fentanyl during induction and inj. Paracetamol at end of surgery after 2 hours. After the procedure patient was reversed maintained on spontaneous ventilation and kept sedated on Ayre's T piece, shifted to paediatric ICU. Patient was kept intubated for next 12 hrs. with sedation maintained on inj. midazolam and Inj. 
paracetamol intravenous for analgesia and was extubated next day morning, after which she was shifted on liquid diet followed by semisolid diet. Child was playful, with a adequate mouth opening and was discharged home on $5^{\text {th }}$ day of surgery. To conclude this case report illustrates, multidisciplinary approach for management of airway in a rare case of syngnathia. Awake nasal FOB can be performed in properly premedicated child by incremental doses of ketamine, which was done in this case.

\section{REFERENCES}

[1] Nagaprasad N, Qureshi MR, Qureshi VF, et al. Rare occurrence of two cases of congenital syngnathia at Osmania General Hospital, Hyderabad, India: A Case Report. Biomed J Sci \& Tech Res 2018;7(2):5773-5.

[2] Broome M, Vial Y, Jacquemont S, et al. Complete maxillomandibular syngnathia in a newborn with multiple congenital malformations. Pediatr Neonatal 2013.

[3] Saxena KN, Bansal P. Endotracheal intubation under local anesthesia and sedation in an infant with difficult airway. J Anaest Clin Pharmacol 2012;28(3):358-60.

[4] Lonnée H, Rashad A, Rahimi GR. Airway management of an infant presenting with syngnthia for surgical correction. Open J Anaesth 2013;3(1):35-7.
[5] Reddy RGV, Ganapathy KS, Sanjay V, et al. Syngnathiacongenital unilateral bony fusion the maxilla and mandible. J Ind Acad Oral \& Med Radiol 2008;20(3):1135 .

[6] Alfery DD, Ward CF, Harwood IR, et al. Airway management for a neonate with congenital fusion of the jaws. Anesthesiology 1979;51(4):340-2.

[7] Burket LW. Congenital bony temporomandibular ankylosis and facial hemiatrophy: a review of the literature and report of a case. J Am Med Assoc 1936;106(20):1719-22.

[8] Weiss M, Engelhardt T. Proposal for the management of the unexpected difficult pediatric airway. Pediatr Anesth 2010;20(5):454-64.

[9] Cook TM, Woodall N, Frerk C, et al. Major complications of airway management in the United Kingdom: results of the 4th National Audit Project of the Royal College of Anaesthetists and the Difficult Airway Society. Part 1: Anaesthesia. Br J Anaesth 2011;106(5):617-31.

[10] The Association of Paediatric Anaesthetists (APA) Guidelines for difficult airway management in children. 2012. http://www.apagbi.org.uk/publications/apaguideline.

[11] Woods AM. Paediatric bronchoscopy, bronchography, and laryngoscopy. In: Berry FA, edr. Anaesthetic management of difficult and routine paediatric patients. New York: Churchill Livingstone 1986: p. 189-248.

[12] Swanson KL, Prakesh UBS, Midthun DE, et al. Flexible bronchoscopic management of airway foreign bodies in children. Chest 2002;121(5):1695-700. 